\title{
Interpositional Arthroplasty for Treatment of ATM Ankylosis
}

\section{Felipe Daniel Burigo Dos Santos ${ }^{1, *}$, Eduarda Braz², Marcelo Rocha Matos ${ }^{3}$, Manuel Otávio Schmitz ${ }^{4}$, Flávio Henrique Silveira Tomazi $^{5}$, Murilo Chiarelli ${ }^{6}$, Jonathas Paggi Claus ${ }^{7}$, Luiz Henrique Marola ${ }^{8}$, and Arthur Castellano ${ }^{8}$}

${ }^{1}$ Resident, Department of Maxillofacial Surgery and Traumatology, Florianópolis, Brazil

${ }^{2}$ General Surgeon, Department of Dentistry, Implant Student, Graduation Unisul, Brazil

${ }^{3}$ Teacher in UNISUL, Surgeon, Department of Oral and Maxillofacial Surgery, Nossa Senhora da Conceição Hospital and Clinical Estomatology, Master's degree in PUCRS, Brazil

${ }^{4}$ Surgeon, Department of Oral and Maxillofacial Surgery, Nossa Senhora da Conceição Hospital, Bucomaxilofacial Surgeon Especialist, Brazil

${ }^{5}$ Surgeon, Department of Oral and Maxillofacial Surgery, Nossa Senhora da Conceição Hospital and Especialist, Master's Degree and PhD student in Cirurgia Bucomaxilofacial PUCRS, Brazil

${ }^{6}$ Surgeon, Department of Oral and Maxillofacial Surgery, Governador Celso Ramos Hospital and private clinic, Florianópolis, Brazil

${ }^{7}$ Surgeon, Department of Oral and Maxillofacial Surgery, Instituto Bucomaxilofacial, Florianópolis, Brazil

${ }^{8}$ Surgeon, Department of Oral and Maxillofacial Surgery, graduate in UFSC, Brazil

*Corresponding author: Felipe Daniel Burigo Dos Santos, Resident, Department of Maxillofacial Surgery and Traumatology, Florianópolis, Brazil, E-mail: felipe_b@hotmail.com.br

Received: 06 Nov, 2019 | Accepted: 28 Sep, 2020 | Published: 02 Oct, 2020

Citation: Dos Santos FDB, Braz E, Matos MR, Schmitz MO, Tomazi FHS, et al. (2020) Interpositional Arthroplasty for Treatment of ATM Ankylosis. J Surg Open Access 6(6): dx.doi.org/10.16966/2470-0991.226

Copyright: (c) 2020 Dos Santos FDB, et al. This is an open-access article distributed under the terms of the Creative Commons Attribution License, which permits unrestricted use, distribution, and reproduction in any medium, provided the original author and source are credited.

\section{Abstract}

Introduction: The temporomandibular joint ankylosis is the union between the surface of the temporal bone in its articular portion and the complex made out of articular disk and the condyle. Its etiology is multifactorial being the trauma with condylar fracture most cited. This alteration causes several functional disorders to the patient, among them the main one is the limitation of mouth opening, which causes difficulty eating, speaking, hygiene, speech and others. The diagnosis is made through a clinic image test. The goal is to show a report of case of ankylosis as well as a literature review.

Development: A 20-years-old patient, male, $5 \mathrm{~mm}$ mouth opening, was diagnosed with ankylosis temporomandibular, treated with bilateral and coronoidectomy and arthroplasty, evolving to a $30 \mathrm{~mm}$ opening.

Conclusion: Interpositional and arthroplasty with shred of the temporal fascia muscle shows good results for being an autograft tissue, the satisfactory result depends on the surgical technique and post operatory cares. Post-surgery follow-ups must be multidisciplinary with a dental surgeon, physiotherapist, phonoaudiologist among other professionals.

Keywords: Temporomandibular joint; Ankylosis; Arthroplasty; Hospital dental service

\section{Introduction}

The Temporomandibular Joint (TMJ) is one of the most complex joints in the human body, its proper functioning determines the mandibular movements that are of great importance for relevant daily functions such as speech, chewing, mouth opening, breathing during sleep $[1,2]$.

Ankylosis is a dysfunction that affects this joint, making the mandibular condyle attached to the glenoid cavity through bone or fibrous tissue $[3,4]$. Signs of limitation on mouth opening and chewing [1]. There are reports of changes in mandibular growth, especially if the patient is in the growth phase. These limitations may subsequently lead to nutritional, aesthetic and psychological problems [1].

The diagnosis is obtained through clinical and radiographic evaluation, including Computed Tomography (CT) and even Third-
Dimensional Reconstructions (3D-CT) [5]. The primary clinical sign of this condition would be the limitation of mouth opening, given the asymptomatic character of the disease. It is indicated that surgery should be scheduled as soon as the diagnosis is made [5].

TMJ ankylosis is classified according to the combination of local (intraorextra-articular) type of tissue involved (bone, fibrous or fibrobone) and the extent of fusion maybe: complete or incomplete [6]. It can still be classified as true or false. In true ankylosis there is a fibrous or bony adhesion between the joint surfaces. False ankylosis results from pathological conditions not directly linked to the joint [6] The most common etiology is trauma followed by infection; rarely its cause is pathological such as rheumatoid arthritis, psoriasis, ankylosing spondylitis or joint neoplasia [2,7]. The treatment is performed surgically in order to restore its form and function [8], covering some options for approach such as: Opening arthroplasty 
(gap arthroplasty), Interpositional arthroplasty, ankylotic mass excision with ligament reconstruction [8].

The most important criteria for graft or material choice are: cost, aesthetic consequences, graft removal, durability, risk of infection, biocompatibility, tolerance of the material to be used and prevention of recurrence [8].

\section{Case Report}

A 20-years-old male patient who had been a victim of a 60-day motorcycle accident attended the outpatient clinic reporting difficulty in mouth opening. He remained in the ICU for 40 days and sought CTBMF service after improvement of the hospital condition.

Clinical examination revealed reduced maximal mouth opening $(<5 \mathrm{~mm})$ and limitation in condylar movements bilaterally (Figure 1$)$. The tomographic exam showed alteration in the condylar morphology, decrease in the articular space and bone fusion between condyles and glenoid cavity bilaterally.

Patient underwent general anesthesia with tracheostomy intubation (previously performed). Bilateral extended preauricular access (Al-Kaiat) was performed to access the temporomandibular joints (Figure 2).

A bilateral interpositional arthroplasty with rotation and interposition of temporal muscle fascia flap to reduce the chances of recurrence (Figure 3).

After bilateral interposicional arthroplasty, a $25 \mathrm{~mm}$ intraoperative opening was achieved, and bilateral coronoidectomy was performed to gain amplitude of opening. After that, the aperture value reached 32 $\mathrm{mm}$. It was then closed by plans.

The patient was instructed to undergo aggressive mouth opening physiotherapy in the first postoperative days. On the seventh day after surgery, the patient had $25 \mathrm{~mm}$ of mouth opening and no facial nerve deficit.

After 30-day reassessment, the patient presented no complaints and had an interincisal opening of $30 \mathrm{~mm}$ (Figure 4).

The patient maintained the follow up with CT scan and clinical examination for two years with Maxilofacial team (Figure 5 and 6) where he presented great evolution in phonation, hygiene, nutrition and speech. We do not choose the temporomandibular joint prosthesis

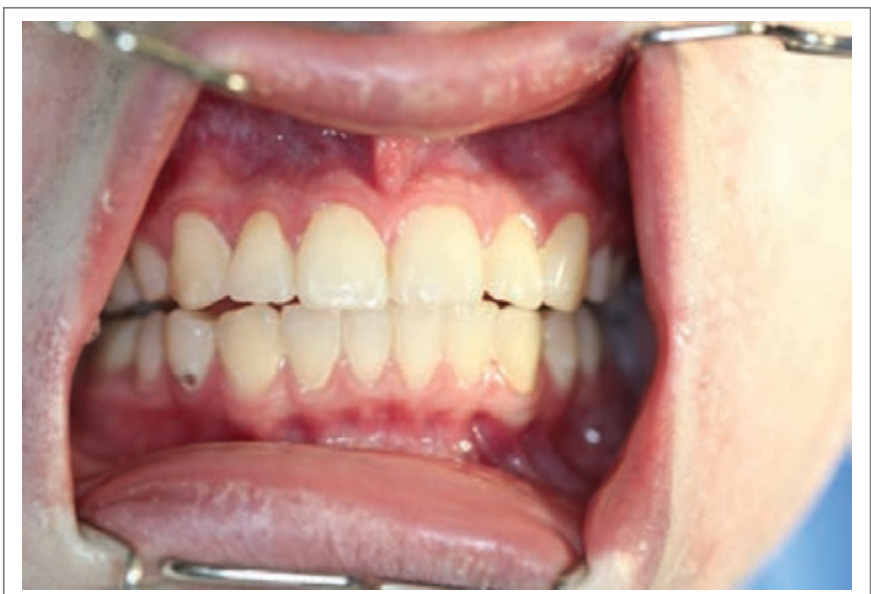

Figure 1: Oclusion view Pre Surgical.

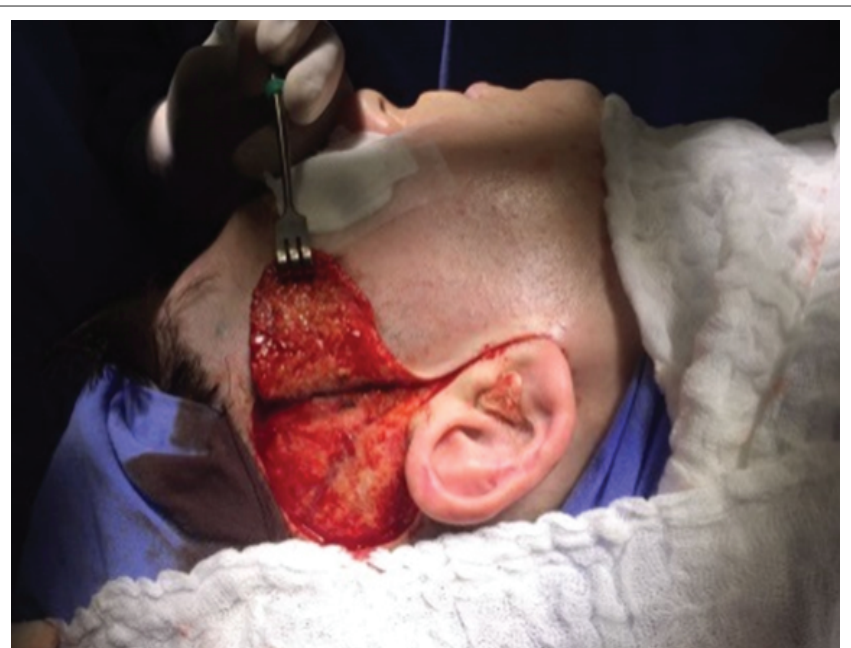

Figure 2: Al-Kaiat Surgical Access.

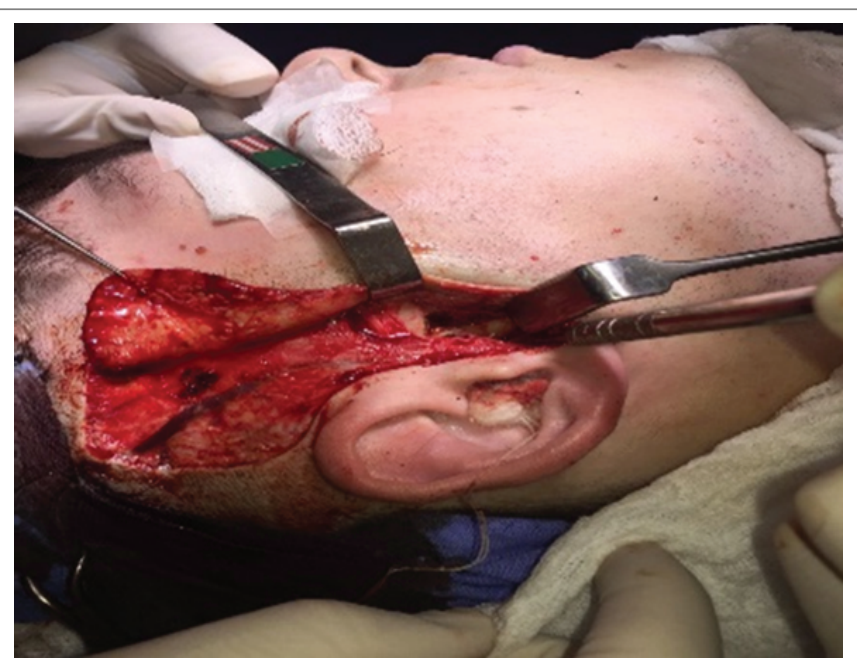

Figure 3: Al-Kaiat Surgical Access with flap of temporal fascia.

for treatment, because it was a public service which has a lot of difficulties to access this form of treatment and material.

\section{Discussion}

TMJ reconstruction should be widely evaluated and discussed to lead the case to a more appropriate treatment, as it is a very complex joint composed of many components, a pattern to be followed in the treatments has not yet been found. However, most authors cite basically three types of treatments that are commonly performed: Gap arthroplasty, interpositional arthroplasty, and TMJ reconstruction excision [8].

Since the first technique is the oldest one used in these cases, it demands a shorter surgery time and lower costs than interpositional arthroplasty. However, this technique has a high rate of reankylosis. The results of studies in the literature are controversial [6,7]. For Aneja V, et al. [9], reconstructive TMJ approaches with either autogenous grafts or alloplastic materials have common complications such as reankylosis, resorption, overgrowth, fracture and pain.

A study by Gupta S, et al. [7] compared the insertion of the temporal fascia with the insertion of a silicone material in the region of the joint, 


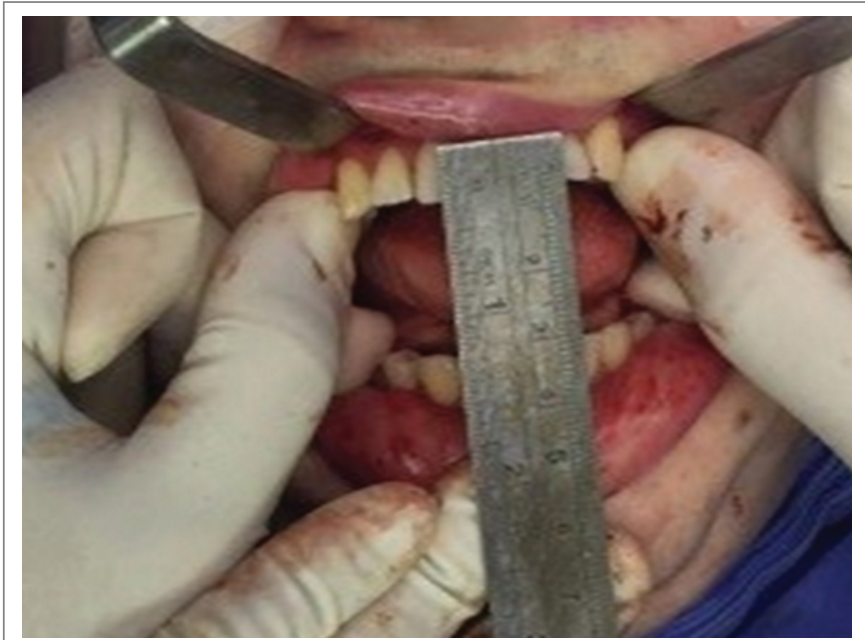

Figure 4: Postoperative mouth opening.

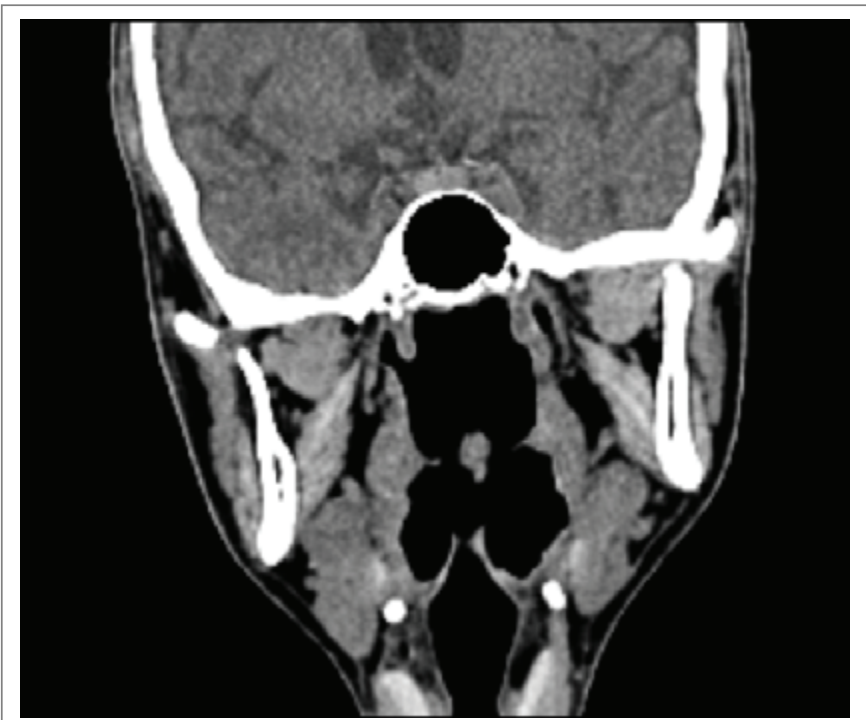

Figure 5: CT scan with 2 years of follow-up.

in relation to the interstitial middle opening and the relapse of group $\mathrm{A}$ (silicone) was $4.6 \%$ and $7.9 \%$ for group B (fascia) from 9 to $10 \%$ both in the $3^{\text {rd }}$ and $6^{\text {th }}$ post operative month respectively. During the first month, there was no significant difference. However, despite its high cost, the silicone material has the same conditions as the temporal fascia graft. Regards the vertical dimension and ensures interincisal opening. Corroborates the study by Qudah MA, et al. [10], where the success of surgical treatment for ankylosis in 8 patients reached $87.5 \%$.

Gupta S, et al. [7] reports that ankylosis is more common in the first decade of life, because children are more active and have poor motor coordination, especially in the first years of life, being easier to occur trauma leading to this change [7].

For Aneja V, et al. [9] the surgical treatment using temporal fascia which was used in this case is more effective than the other treatments, both in terms of functional stability, recurrence and economic.

\section{Conclusion}

Based on the literature review and the case presentation described

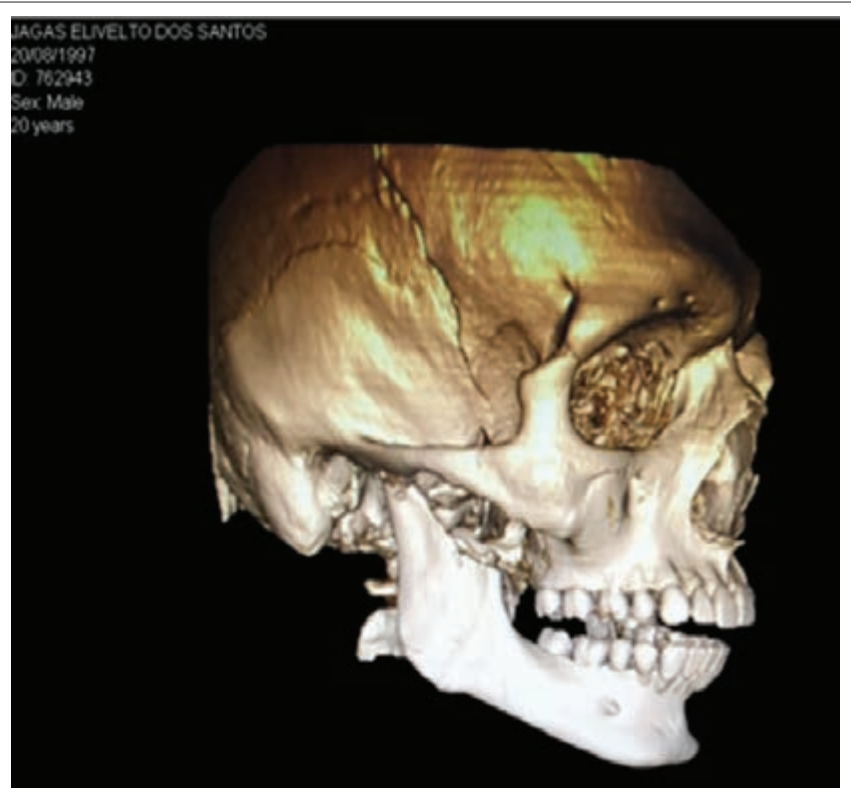

Figure 6: CT scan-3D reconstructionwith 2 years of follow-up.

here, it was concluded that clinical, physical and imaging exams are essential for a faithful diagnosis of the case. The interpositional arthroplasty technique is an indicated and efficient surgical technique for the surgical treatment of temporomandiular joint ankylosis. The advantages of the technique presented in this case are its low cost, and being a graft with the patient's own temporal fascia, there is no reaction to foreign body such as infection, extrusion and displacement of the interposed material. The surgical procedure of the interpositional arthroplasty technique requires follow-up of the Buccomaxillofacial Surgeon because there is a possibility of ankylosis recurrence. The technique has some disadvantages such as requiring more operative time because there is a need for a graft donor site, which may result in a more difficult postoperative for the patient.

\section{References}

1. Genaro KF, de Oliveira Freitas Passos DCB, Berretin-Felix G, Trindade Júnior AS (2013) Atividade muscular da mastigação na anquilose temporomandibular. Rev Cefac 15: 111-118.

2. Brown $E$, Wilson $M H$, Revington $P$ (2016) Single-stage temporomandibular joint arthroplasty in a patient with complete bony ankylosis and previous extradural haematoma. BMJ Case Rep.

3. Madeira MC (2001) Anatomia da face: bases anátomo-funcionais para a prática odontológica. $3^{\text {rd }}$ Edition, Sarvier.

4. Miloro M, Ghali GE, Larsen PE (2009) Príncipios de cirurgia bucomaxilofacial de Peterson. Santos, Brazil.

5. El-hakim IE, Metwalli SA (2002) Imaging of temporomandibular joint ankylosis. A new radiographic classification. Dentomaxillofac radiol 31: 19-23.

6. Manganello-Souza LC, Mariani PB (2003) Temporomandibular joint ankylosis: Report of 14 cases. Int J Oral Maxillofac Surg 32: 24-29.

7. Gupta S, Gupta H, Mohammed S, Mehra H, Natu SS, et al. (2016) Silicone vs. temporalis fascia interposition in TMJ ankylosis: A comparison. J Oral Biol Craniofac Res 6: 107-110.

8. Vieira ACF, Rabelo LRS (2009) Anquilose de ATM em crianças: aspectos de interesse cirúrgico. Rev Cir Traumatol Buco-Maxilo-Fac 9: 15-24. 
9. Aneja V, Raval R, Bansal A, Kumawat V, Kaur J, et al. (2016) Interpositional Gap Arthroplasty by Versatile Pedicled Temporalis Myofascial Flap in the Management of Temporomandibular Joint Ankylosis-A Case Series Study. J Clin Diagn Res 10: ZR01-ZR04.

10. Qudah MA, Qudeimat MA, Al-Maaita J (2005) Treatment of TMJ ankylosis in Jordanian children-a comparison of two surgical techniques. J Cranio Maxillofac Surg 33: 30-36. 